A8

doi: 10.14232/ syrpharmacognosy.2021.a8

\title{
Isolation and synthesis of 6-gingerol and 6-gingerdione derivatives
}

\section{Sara Hassan Hassan Ahmed}

Email: sara.hassan@pharm.u-szeged.hu

Ginger (Zingiber officinale Roscoe) has been used as a spice and a traditional remedy since ancient times, especially in Chinese herbal medicine [1,2]. A wide array of bioactivities were reported regarding ginger extract, e.g, antioxidant, anti-inflammatory, antiemetic, anticancer activity [3]. Most of the bioactivities had been correlated to gingerols and shogaols, the most abundant secondry metabolites in ginger [4].

In our work, we aimed to investigate the chemical space around 6-gingerol by introducing different changes in the skeleton and investigating the bioactivity of the resulting derivatives. The current work also focuses on the total synthesis of 6-gingerdione, another important compound in ginger root, and its heterocyclic analogues. So far, six molecules have been synthesized and characterized; the final purification and structure elucidation of further derivatives are currently in progress.

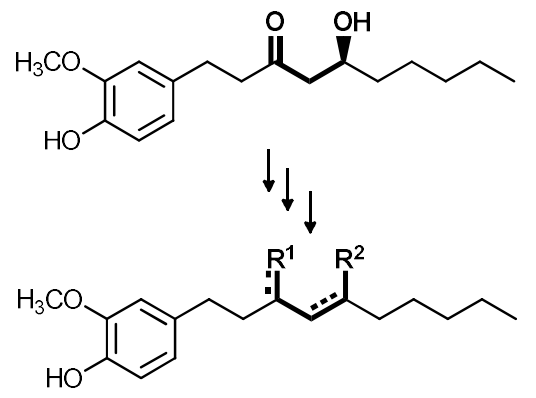<smiles>[R]c1ccc(/C=C/C(=O)CC(=O)CCCCC)cc1OC</smiles><smiles></smiles>

Supervisors: Attila Hunyadi, Timea Halasi-Gonda

\section{Acknowledgements:}

This work was supported by the National Research, Development and Innovation Office, Hungary (NKFIH; K-134704), and the Ministry of Human Capacities, Hungary grant 20391-3/2018/FEKUSTRAT.

\section{References}

[1] Leoni, A., et al. Natural Product Research 2018; 32(18): 2139-2146.

[2] Sana, N., et al. Anti-Cancer Agents in Medicinal Chemistry 2021; 21(4): 428-432.

[3] Mao, Q.Q., et al. Foods 2019; 8(6).

[4] de Lima, R.M.T., et al. Phytother Res 2018; 32(10): 1885-1907. 